Article

\title{
Evaluation of Water Resources Carrying Capacity in Guiyang City
}

\author{
Li Ren ${ }^{1}$, Jiachen Gao ${ }^{1}$, Shuping Song ${ }^{1}$, Zhuoman $\mathrm{Li}^{1}$ and Jianjun $\mathrm{Ni}^{2, * \mathbb{C}}$ \\ 1 Faculty of Hydrology and Water Resources, College of Hydrology, Hohai University, Nanjing 210098, China; \\ renli@hhu.edu.cn (L.R.); 191301010078@hhu.edu.cn (J.G.); 201301010081@hhu.edu.cn (S.S.); \\ 191601010015@hhu.edu.cn (Z.L.) \\ 2 Faculty of Hydrology and Water Resources, College of IOT Engineering, Hohai University, \\ Changzhou 213022, China \\ * Correspondence: njjhhuc@gmail.com; Tel.: +86-13656114896
}

check for

updates

Citation: Ren, L.; Gao, J.; Song, S.; Li, Z.; Ni, J. Evaluation of Water Resources Carrying Capacity in Guiyang City. Water 2021, 13, 2155. https://doi.org/10.3390/w13162155

Academic Editor: Roko Andricevic

Received: 8 June 2021

Accepted: 2 August 2021

Published: 5 August 2021

Publisher's Note: MDPI stays neutral with regard to jurisdictional claims in published maps and institutional affiliations.

Copyright: (c) 2021 by the authors. Licensee MDPI, Basel, Switzerland. This article is an open access article distributed under the terms and conditions of the Creative Commons Attribution (CC BY) license (https:// creativecommons.org/licenses/by/ $4.0 /)$.

\begin{abstract}
Based on the situation of Guiyang's water resources, society, economy, ecology, etc., a comprehensive evaluation index system of Guiyang's water resources carrying capacity is established by selecting appropriate indexes. Based on the analytic hierarchy process (AHP) and the entropy method, an evaluation model of Guiyang's water resources carrying capacity is constructed. The results showed that the comprehensive evaluation value of water resources carrying capacity in Guiyang City increased by nearly 53\% from 2009 to 2018, and the regulation and control force of water resources carrying capacity and water resources carrying pressure showed an upward trend. Within ten years, the total comprehensive evaluation value of Guiyang is 0.4503 - close to $\mathrm{H}_{2}$ level一and the membership degree of evaluation results over the years to $\mathrm{H}_{2}$ is greater than that of $\mathrm{H}_{1}$ and $\mathrm{H}_{3}$. $\mathrm{H}_{1}, \mathrm{H}_{2}$, and $\mathrm{H}_{3}$ are the three standard grades of water resources carrying capacity index, and the degree of carrying capacity represented is decreasing in turn. This indicated that at this stage, water resources can maintain the rapid development of the social economy, and that there is still some development potential. The research results have certain reference value for Guiyang's development and utilization of water resources.
\end{abstract}

Keywords: water resources carrying capacity; analytic hierarchy process; entropy method; fuzzy analysis; Guiyang City

\section{Foreword}

A shortage of water resources is one of the most important natural resources problems facing humankind today. The water resource crisis will bring great threats to the economic development of various countries. For example, China is currently short of water resources due to the uneven spatial and temporal distribution of water resources and the mismatch of water and soil resources, which is a factor in the restriction of sustainable social and economic development in China [1]. Regional water resources carrying capacity has become a hot topic in water resources research. Regional water resources carrying capacity refers to the reasonable scale that measures the degree to which the regional water resources system can support sustainable social and economic development under the condition of a certain level of economic, social, and technological development. It also evaluates the premise of the coordination between the healthy development of ecology and environment and sustainable social and economic development [2]. Correct evaluation of water resources carrying capacity can guide the rational utilization of water resources, and is of great significance to promote harmonious social and economic development $[3,4]$. At present, the evaluation methods of water resources carrying capacity in China mainly include principal component analysis [5], system dynamics method [6], ecological footprint method [7], and fuzzy analysis [8]. For example, Hong Xinyan [5] used principal component analysis to evaluate Xinjiang's water resources carrying capacity, but in the evaluation process, it failed 
to hierarchically divide the carrying capacity of water resources in order to intuitively express it. Guo Weihong et al. [6] used a system dynamics model and predicted the water resources carrying capacity of Henan Province. However, the establishment of the system dynamics model is only the result of subjective abstraction and generalization after the research and insight of some specific systems, and its applicability needs to be further verified. Zhang Qian et al. [7] used a water ecological footprint model in addition to other models in order to analyze Chongqing's water ecological footprint, water resources carrying capacity, and water resources development and utilization from 2003 to 2016. However, the ecological footprint method is a calculation method based on the current static data, and thus the conclusion is instantaneous and cannot reflect the future development trend. Sun Kang et al. [8] concluded that the water resources carrying capacity of Wuhu City showed a gradual increasing trend from 2006 to 2015 based on the fuzzy comprehensive evaluation, but only when using the analytic hierarchy process to establish the weight of each index to ensure it has certain subjectivity. However, the current evaluation index system of water resources carrying capacity is not complete, and the determination of weights-the relative importance of each indicator-is uncertain. There are differences in the utilization of water resources in various regions, and further research is still needed. Guiyang is a city with a typical karst landform. Its unique surface-underground water storage structure results in serious seepage of surface water, and leads to a high cost of water resources development and utilization. This is the prominent problem of an engineering water shortage [9]. In this study, a comprehensive evaluation index system containing 15 indicators was established, and the weights were established through the coupling of the analytic hierarchy process and the entropy weight method. While absorbing the experience of experts, the amount of objective information is comprehensively considered in order to avoid the subjectivity caused by personal preferences. The evaluation model of water resources carrying capacity based on fuzzy analysis was established to evaluate the water resources carrying capacity of Guiyang from 2009 to 2018, and to determine the membership degree and comprehensive evaluation value of the evaluation results over the years. The overall objective is to provide guidance for the future development and utilization of water resources in Guiyang City.

\section{Study Method}

\subsection{Establishment and Grading of the Index System}

The evaluation index system of water resources carrying capacity is the core of the study on the regional water resources carrying capacity [10]. To fully and truly reflect Guiyang's water resources carrying capacity, the index system in the national water resources supply and demand analysis and the existing related research [9,11-13] are taken for reference for this study. In view of the prominent contradiction between supply and demand of water resources and the severe water pollution in Guiyang City, the index selection and analysis are carried out from three aspects, including the main support force of water resources carrying, the control force of water resources carrying, and the object pressure of water resources carrying. Fifteen influencing factors are selected to construct the evaluation index system of water resources carrying capacity in Guiyang City, which are composed of the target layer, the criterion layer, and the index layer (Table 1). The selected factors in the index system are of three grades: $\mathrm{H}_{1}$ indicates that the water resources carrying capacity of the region is in a sustainable state, and that there is great potential for development; $\mathrm{H} 3$ indicates that the water resources carrying capacity of the region is close to the saturation value, the water resources are utilized to the maximum extent, and the contradiction between supply and demand of water resources obviously restricts social and economic development and aggravates the vulnerability of ecological environment; and $\mathrm{H}_{2}$ is a grade between $\mathrm{H}_{1}$ and $\mathrm{H}_{3}$, indicating that the water resources carrying capacity of the region is moderate but that there is still room for further development and utilization. In order to quantitatively reflect the carrying capacity, $\mathrm{z}_{1}=0.95, \mathrm{z}_{2}=0.5$ and $\mathrm{z}_{3}=0.05$ [14] are assigned to the three grades-namely $\mathrm{H}_{1}, \mathrm{H}_{2}$, and $\mathrm{H}_{3}-$ within the range of $0-1$. Therefore, the calculation formula for the comprehensive score value $\mathrm{Z}$ of water resources carrying 
capacity is $Z=0.95 z_{1}+0.5 z_{2}+0.05 z_{3}$. The higher the value of the comprehensive score value obtained, the stronger the water resources carrying capacity. This is shown in Table 1 for specific rating indexes and the grading standard.

Table 1. Comprehensive rating indexes and grading standard of water resources carrying capacity.

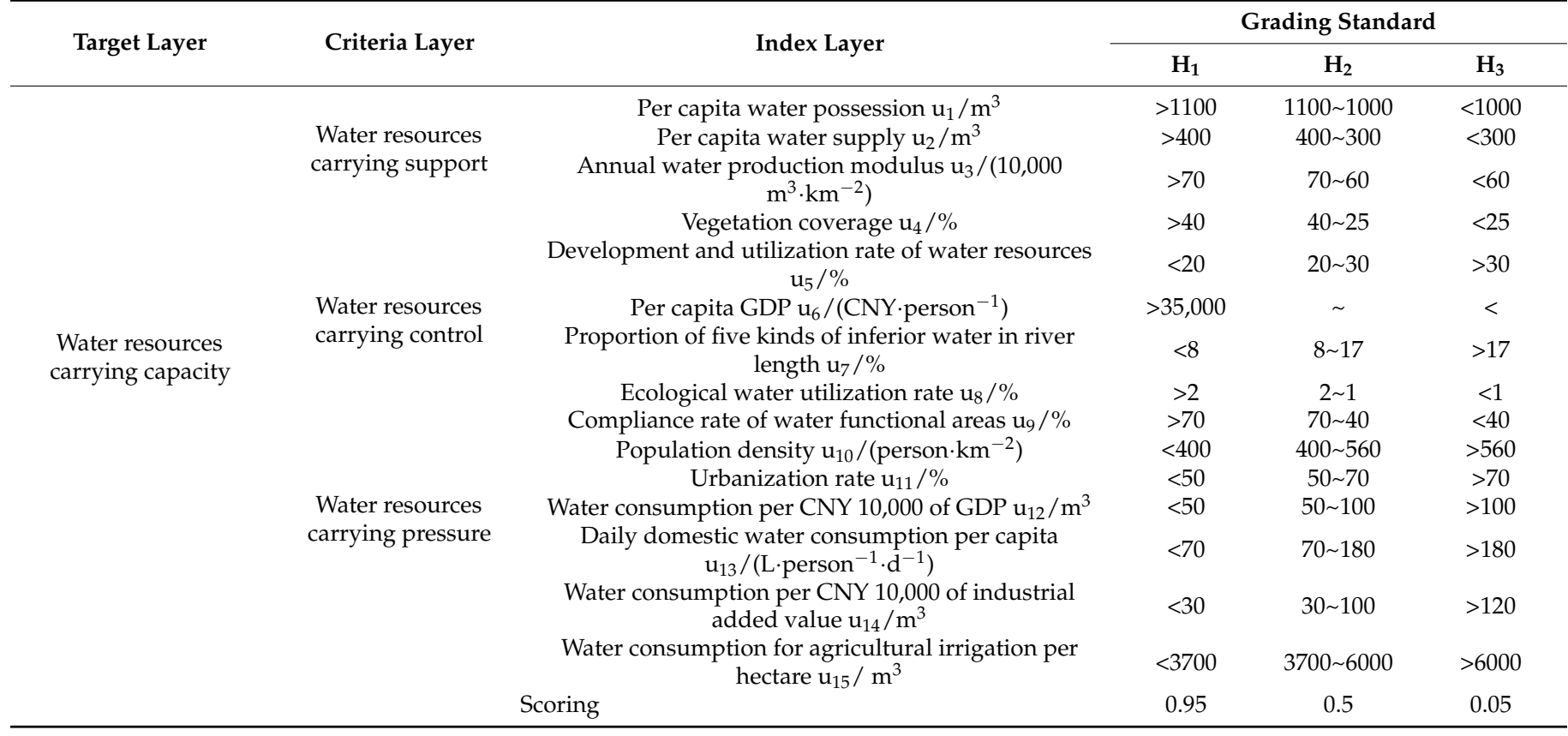

\subsection{Determination of Index Weights}

To ensure the reliability of the evaluation results, subjective method (analytic hierarchy process) and objective method (entropy method) are combined to assign weights. Since there is no preference for the two methods, the arithmetic average method is used as the combined weighting method.

\subsubsection{Calculation of Subjective Weight by Analytic Hierarchy Process}

The analytic hierarchy process (AHP) was proposed in the early 1970s [15], and effectively determines the weight value of each index from qualitative analysis to quantitative integration. It is a typical multi-criteria decision-making method, which combines subjective judgment with objective facts, expresses the views of decision makers quantitatively, and reflects the thinking of decomposition, judgment, and synthesis in decision-making. The analytic hierarchy process can divide a complex system into an orderly hierarchical structure. The weight coefficient of the relative importance ranking of all indexes can be determined based on the subjective judgment of the importance of each index to the subjects, according to expert experience. The key problem is to calculate the maximum eigenvalue $\lambda_{\max }$ of the judgment matrix and its corresponding eigenvector $\mathrm{W}$.

(1) On the basis of the comprehensive evaluation index system, score the relative importance between two factors at the same level, using the numbers 1-9 and their reciprocals as scales [15], and construct a judgment matrix $U^{\prime}=\left(\mathrm{u}_{i j}\right)_{n \times n}$.

(2) Calculate the weight vector $W^{\prime}=\left[W_{1}, W_{2}, \ldots, W_{n}\right]$ T of the judgment matrix by the geometric average method. See Equation (1).

$$
W_{i}=\frac{\left(\prod_{j=1}^{n} u_{i j}\right)^{\frac{1}{n}}}{\sum_{i=1}^{n}\left(\prod_{j=1}^{n} u_{i j}\right)^{\frac{1}{n}}}, i=1,2, \ldots, n
$$


In the formula, $W i$ is the weight of the $i$ line; $\mathrm{u}_{i j}$ is the element of the $i$ line and the $j$ column of the judgment matrix $U^{\prime}$.

(3) Calculate the maximum eigenvalue $\lambda_{\max }$. See Equation (2).

$$
\lambda_{\max }=\sum_{i=1}^{n} \frac{\left(U^{\prime} W\right)_{i}}{n W_{i}}
$$

In the formula, $\lambda_{\max }$ is the maximum eigenvalue of the judgment matrix, while $U^{\prime}$ is the judgment matrix.

(4) In order to judge whether the fuzzy matrix has satisfactory consistency, a consistency test is required. The negative mean value of the eigenvalues-other than the maximum eigenvalue $\lambda_{\max }$ of the judgment matrix-is used as a numerical index to measure whether the judgment matrix is consistent [16]; when CR $\leq 0.1$, the consistency is satisfactory. When $\mathrm{CR}>0.1$ ( $\mathrm{CR}$ is the calculated consistency ratio), the judgment matrix needs to be corrected.

$$
C I=\frac{\lambda_{\max }-n}{(n-1) R I}
$$

In the formula, $C I$ is the consistency index and $n$ is the order of the judgment matrix.

\subsubsection{Calculation of Objective Weights by Entropy Method}

The entropy method is a mathematical method used to calculate a comprehensive index on the basis of comprehensively considering the amount of information provided by various factors. Weights are mainly determined according to the amount of information transmitted by each index to decision makers [17]. In regard to the evaluation of an object, if its value of a certain index differs greatly and the entropy value is small, it can be inferred that the index provides a large amount of effective information and the weight of the index should be large [18]; under the opposite condition, the weight of the index should be small. The steps of determining index weights by entropy method are as follows:

(1) Construct a judgment matrix $P=\left(p_{i j}\right) m \times n$, according to the data of $m$ evaluation indexes in $n$ years, and process the data to eliminate the influence of dimensions and orders of magnitude. For cost indexes (such as urbanization rate) where the lowest is the best, refer to Equation (4) for normalization. For profitability indexes (such as per capita water supply) where the highest is the best, refer to Equation (5) for normalization.

$$
\begin{aligned}
& p_{i j}^{\prime}=\left[\max _{j}\left\{p_{i j}\right\}-p_{i j}\right] /\left[\max _{j}\left\{p_{i j}\right\}-\min _{j}\left\{p_{i j}\right\}\right] \\
& p_{i j}^{\prime}=\left[p_{i j}-\min _{j}\left\{p_{i j}\right\}\right] /\left[\max _{j}\left\{p_{i j}\right\}-\min _{j}\left\{p_{i j}\right\}\right]
\end{aligned}
$$

where $p_{i j}$ is the statistical value of the $i$-th index in the $n$-th year; $\max _{j}\left\{p_{i j}\right\}$ and $\min _{j}\left\{p_{i j}\right\}$ are the maximum value and the minimum value of the $i$-th index in the $n$-th year, respectively; $p_{i j}{ }^{\prime}$ is the normalized data.

(2) In the evaluation involving the data of $m$ indexes in $n$ years, the entropy value of the i-th index can be calculated according to Equation (6).

$$
E_{i}=\left(-\sum_{j=1}^{n} f_{i j} \ln f_{i j}\right) / \ln n
$$

where: $f_{i j}$ can be calculated according to Equation (7).

$$
f_{i j}=\left(1+p_{i j}^{\prime}\right) / \sum_{j=1}^{n}\left(1+p_{i j}^{\prime}\right)
$$


(3) According to the entropy values of the m evaluation indexes, the entropy weight can be calculated according to Equation (8).

$$
w_{i}^{\prime \prime}=\left(1-E_{i}\right) /\left(m-\sum_{i=1}^{m} E_{i}\right)
$$

According to Equation (9), the weight of the previous criteria layer can be calculated with the weights of all indexes.

$$
W^{\prime \prime}=\left[w_{i}^{\prime \prime}\left(1-E_{i}\right)\right] /\left[\sum_{i=1}^{m} w_{i}^{\prime \prime}\left(1-E_{i}\right)\right]
$$

\subsection{Determination of Membership Function}

The indexes near the critical value may have small numerical correlation but completely different evaluation levels. In order to eliminate this jump phenomenon, such indexes should be fuzzified [19]. Set the membership degree of the interval midpoint value of $\mathrm{H}_{2}$ to be 1 , the membership degree of the two critical points to be 0.5 , and the value decreases from the middle to both sides.

Set the critical values of $\mathrm{H}_{1}$ and $\mathrm{H}_{2}$ to be $k_{1}$, the critical values of $\mathrm{H}_{2}$ and $\mathrm{H}_{3}$ to be $k_{3}$, the interval midpoint value of $\mathrm{H}_{2}$ to be $k_{2}$, and $k_{2}=\left(k_{1}+k_{3}\right) / 2$. The evaluation factors are divided into positive and negative effect factors according to their effect on the objects being evaluated. As shown in Equations (10)-(12) [20], for the calculation formulas of membership functions of positive influence factors (such as $\mathrm{u}_{1}, \mathrm{u}_{2}, \mathrm{u}_{3}, \mathrm{u}_{4}, \mathrm{u}_{6}, \mathrm{u}_{8}$, and $\mathrm{u}_{9}$ ) relative to each evaluation grade:

$$
\begin{aligned}
& W_{H 1}= \begin{cases}0.5\left(1+\frac{\mathrm{u}_{i}-k_{1}}{\mathrm{u}_{2}-k_{2}}\right), & u_{i}>k_{1} \\
0.5\left(1-\frac{\mathrm{u}_{i}-k_{1}}{k_{2}-k_{1}}\right), & k_{2}<u_{i} \leq k_{1} \\
0, & u_{i} \leq k_{2}\end{cases} \\
& W_{H 2}= \begin{cases}0.5\left(1-\frac{\mathrm{u}_{i}-k_{1}}{\mathrm{u}_{i}-k_{2}}\right), & u_{i}>k_{1} \\
0.5\left(1+\frac{\mathrm{u}_{i}-k_{1}}{k_{2}-k_{1}}\right), & k_{2}<u_{i} \leq k_{1} \\
0.5\left(1+\frac{\mathrm{u}_{i}-k_{3}}{k_{2}-k_{3}}\right), & k_{3}<u_{i} \leq k_{2} \\
0.5\left(1-\frac{\mathrm{u}_{i}-k_{3}}{\mathrm{u}_{i}-k_{2}}\right), & u_{i} \leq k_{3}\end{cases} \\
& W_{H 3}= \begin{cases}0, & \mathrm{u}_{i}>k_{2} \\
0.5\left(1-\frac{\mathrm{u}_{i}-k_{3}}{k_{2}-k_{3}}\right), & k_{3}<u_{i} \leq k_{2} \\
0.5\left(1+\frac{k_{3}-\mathrm{u}_{i}}{k_{2}-\mathbf{u}_{i}}\right), & u_{i} \leq k_{3}\end{cases}
\end{aligned}
$$

For membership functions of the negative effect factors, the interval notations of $u_{\mathrm{i}}$ should be changed from " $<$ " to " $>$ " and from " $\leq$ " to " $\geq$ " on the right side of the above equation.

\subsection{Fuzzy Comprehensive Evaluation Model}

Construct a set of the objects being evaluated: $U=\left\{\mathrm{u}_{1}, \mathrm{u}_{2}, \ldots \mathrm{u}_{m}\right\}$, where $\mathrm{u}_{i}(i=1 \ldots$ $m)$ are the $m$ evaluation indexes of the objects being evaluated. Construct an evaluation grade set: $\mathrm{V}=\left\{\mathrm{v}_{1}, \mathrm{v}_{2}, \ldots \mathrm{v}_{\mathrm{n}}\right\}$, where $\mathrm{v}_{\mathrm{i}}(\mathrm{i}=1 \ldots n)$ are the $\mathrm{n}$ evaluation grades of the objects being evaluated. Determine the degree of different evaluation grades of each object being evaluated in the evaluation grade set, that is, the membership degree expressed by $r_{i j}$, thus obtaining a matrix R:

$$
R=\left(\begin{array}{ccc}
r_{11} & \ldots & r_{1 n} \\
\vdots & \ddots & \vdots \\
r_{m 1} & \cdots & r_{m n}
\end{array}\right)
$$


Comprehensive evaluation matrix:

$$
B=W \times R
$$

where the weight matrix $W=\left(W_{1}, W_{2}, \ldots, W_{n}\right)$ are the weights assigned to all evaluation factors according to their influence on the water resources carrying capacity. $B=\left(b_{1}, b_{2}\right.$, $\left.\ldots b_{j}\right)$, and $b_{j}$ is the membership degree of the grade $v_{j}$ to the fuzzy subset $B$ obtained by the comprehensive evaluation, reflecting the result of the comprehensive evaluation. Then, calculate the comprehensive evaluation value of regional water resources carrying capacity with the scores $\mathrm{z}_{1}, \mathrm{z}_{2}$ and $\mathrm{z}_{3}$ corresponding to the grading indexes $\mathrm{H}_{1}, \mathrm{H}_{2}$, and $\mathrm{H}_{3}$.

\section{Evaluation of Guiyang's Water Resources Carrying Capacity}

The data used in this study is mainly from the Guiyang Water Resources Bulletin (2009-2018) [21] and the Statistical Bulletin of Guiyang's National Economic and Social Development (2009-2018) [22]. Table 2 indicates the actual index values of Guiyang from 2009 to 2018. According to the grading standard in Table 1, the evaluation matrix $\mathrm{R}$ is calculated by using the membership function calculation Formulas (10) (12). The membership degrees of each index to grades $\mathrm{H}_{1}, \mathrm{H}_{2}$, and $\mathrm{H}_{3}$ are calculated. Due to the immense amount of data, only the data of 2018 is taken as an example, as shown in Equation (15). The analytic hierarchy process and the entropy method are used to calculate the weight of each index to the target layer, and combination weighting is done, as shown in Table 3 . The comprehensive evaluation matrix and $b_{1}, b_{2}$, and $b_{3}$ are obtained according to Equation (14), and the comprehensive evaluation value of Guiyang's water resources carrying capacity is obtained according to the score, as shown in Table 4. The diagram of the changes in the comprehensive evaluation value and the evaluation indexes of all subsystems is drawn, as shown in Figure 1.

$$
R_{2018}=\left(\begin{array}{ccc}
0 & 0.1092 & 0.8908 \\
0 & 0.2061 & 0.7939 \\
0 & 0.4808 & 0.5192 \\
0.8077 & 0.1923 & 0 \\
0.18 & 0.82 & 0 \\
0.9264 & 0.0736 & 0 \\
0.6691 & 0.3309 & 0 \\
0.7642 & 0.2358 & 0 \\
0.735 & 0.265 & 0 \\
0 & 0.3134 & 0.6866 \\
0 & 0.324 & 0.676 \\
0.7259 & 0.2741 & 0 \\
0.0533 & 0.9467 & 0 \\
0.3267 & 0.6733 & 0 \\
0.2247 & 0.7753 & 0
\end{array}\right)
$$


Table 2. Evaluation index values of Guiyang's water resources carrying capacity from 2009 to 2018.

\begin{tabular}{|c|c|c|c|c|c|c|c|c|c|c|}
\hline \multirow{2}{*}{ Index } & \multicolumn{10}{|c|}{ Year } \\
\hline & 2009 & 2010 & 2011 & 2012 & 2013 & 2014 & 2015 & 2016 & 2017 & 2018 \\
\hline $\mathrm{u} 1$ & 1076.23 & 769.66 & 616.28 & 1127.88 & 742.54 & 1275.15 & 1044.61 & 693.03 & 1096.42 & 820.99 \\
\hline $\mathrm{u} 2$ & 278.4 & 275.22 & 231.03 & 226.9 & 231.3 & 232.3 & 227.4 & 232.7 & 224.3 & 228.7 \\
\hline $\mathrm{u} 3$ & 49.17 & 35.7 & 33.7 & 62.5 & 41.8 & 72.3 & 60.1 & 40.5 & 65.5 & 59.8 \\
\hline $\mathrm{u} 4$ & 42.3 & 42.3 & 42.8 & 43.15 & 43.5 & 45 & 45.5 & 46.5 & 48.66 & 52.0 \\
\hline $\mathrm{u} 5$ & 25.6 & 35.6 & 37.5 & 20.1 & 31.2 & 18.2 & 21.8 & 33.6 & 20.5 & 23.2 \\
\hline u6 & 24,590 & 30,064 & 31,481 & 38,194 & 48,862 & 55,018 & 63,003 & 67,771 & 74,493 & 78,449 \\
\hline $\mathrm{u} 7$ & 23.6 & 15.7 & 16.6 & 16.6 & 16.6 & 7 & 24.3 & 7 & 6 & 5.7 \\
\hline $\mathrm{u} 8$ & 1.37 & 1.36 & 1.87 & 2.38 & 1.34 & 1.19 & 1.49 & 1.59 & 1.81 & 2.56 \\
\hline u9 & 33.2 & 36.5 & 39.2 & 42.9 & 47.8 & 58.8 & 58.8 & 64.7 & 76.5 & 83.3 \\
\hline $\mathrm{u} 10$ & 456.90 & 464.46 & 546.84 & 554.11 & 562.85 & 567.09 & 575.28 & 584.62 & 597.71 & 607.65 \\
\hline $\mathrm{u} 11$ & 67 & 68.18 & 69.2 & 70.53 & 72 & 73.2 & 73.25 & 74.16 & 74.8 & 75.43 \\
\hline $\mathrm{u} 12$ & 113.2 & 91.5 & 73.4 & 59.4 & 50.2 & 42.4 & 36.4 & 34.6 & 30.4 & 29.4 \\
\hline u13 & 124.64 & 124.08 & 140.31 & 112.01 & 105.42 & 111.73 & 114.47 & 115.03 & 115.88 & 119.14 \\
\hline $\mathrm{u} 14$ & 168.2 & 155.3 & 105.3 & 88.6 & 74.3 & 60.2 & 53.3 & 50.2 & 43.9 & 45.6 \\
\hline u15 & 6750.29 & 5750.66 & 5421.82 & 5096.62 & 4666.01 & 4756.40 & 4781.04 & 4860.45 & 4404.21 & 4333.23 \\
\hline
\end{tabular}

Table 3. Weight of each index of Guiyang's water resources carrying capacity.

\begin{tabular}{|c|c|c|c|c|c|c|c|c|c|c|c|c|}
\hline \multicolumn{6}{|c|}{ Subjective Weighting } & \multicolumn{6}{|c|}{ Objective Weighting } & \multirow{2}{*}{$\begin{array}{c}\begin{array}{c}\text { Combination } \\
\text { Weighting }\end{array} \\
\text { Weight }\end{array}$} \\
\hline $\begin{array}{l}\text { Target } \\
\text { Layer }\end{array}$ & $\begin{array}{c}\text { Criteria } \\
\text { Layer }\end{array}$ & $\begin{array}{l}\text { Weight of } \\
\text { the Criteria } \\
\text { Layer }\end{array}$ & $\begin{array}{l}\text { Index } \\
\text { Layer }\end{array}$ & $\begin{array}{l}\text { Weight of } \\
\text { the Index } \\
\text { Layer }\end{array}$ & Weight & $\begin{array}{l}\text { Target } \\
\text { Layer }\end{array}$ & $\begin{array}{c}\text { Criteria } \\
\text { Layer }\end{array}$ & $\begin{array}{l}\text { Weight of } \\
\text { the } \\
\text { Criteria } \\
\text { Layer }\end{array}$ & $\begin{array}{l}\text { Index } \\
\text { Layer }\end{array}$ & $\begin{array}{l}\text { Weight of } \\
\text { the Index } \\
\text { Layer }\end{array}$ & Weight & \\
\hline \multirow{15}{*}{ A } & \multirow{5}{*}{ B1 } & \multirow{4}{*}{0.1634} & $\mathrm{u}_{1}$ & 0.0969 & 0.0158 & \multirow{15}{*}{ A } & \multirow{4}{*}{ B1 } & \multirow{4}{*}{0.4738} & $\mathrm{u}_{1}$ & 0.1538 & 0.0729 & 0.0444 \\
\hline & & & $\mathrm{u}_{2}$ & 0.4348 & 0.0710 & & & & $\mathrm{u}_{2}$ & 0.3794 & 0.1798 & 0.1254 \\
\hline & & & $\mathrm{u}_{3}$ & 0.1820 & 0.0297 & & & & $\mathrm{u}_{3}$ & 0.1696 & 0.0804 & 0.0550 \\
\hline & & & $\mathrm{u}_{4}$ & 0.2863 & 0.0468 & & & & $\mathrm{u}_{4}$ & 0.2972 & 0.1408 & 0.0938 \\
\hline & & \multirow{5}{*}{0.2970} & $\mathrm{u}_{5}$ & 0.0929 & 0.0276 & & \multirow{5}{*}{ B2 } & \multirow{5}{*}{0.2881} & $\mathrm{u}_{5}$ & 0.1675 & 0.0483 & 0.0379 \\
\hline & \multirow{4}{*}{ B2 } & & $\mathrm{u}_{6}$ & 0.0464 & 0.0138 & & & & $\mathrm{u}_{6}$ & 0.1924 & 0.0554 & 0.0346 \\
\hline & & & $\mathrm{u}_{7}$ & 0.4081 & 0.1212 & & & & $\mathrm{u}_{7}$ & 0.1767 & 0.0509 & 0.0861 \\
\hline & & & $\mathrm{u}_{8}$ & 0.1767 & 0.0525 & & & & $\mathrm{u}_{8}$ & 0.2428 & 0.0700 & 0.0612 \\
\hline & & & $\mathrm{u}_{9}$ & 0.2760 & 0.0820 & & & & $\mathrm{u}_{9}$ & 0.2206 & 0.0636 & 0.0728 \\
\hline & \multirow{6}{*}{ B3 } & \multirow{6}{*}{0.5396} & $\mathrm{u}_{10}$ & 0.2589 & 0.1397 & & \multirow{6}{*}{ B3 } & \multirow{6}{*}{0.2381} & $\mathrm{u}_{10}$ & 0.2811 & 0.0669 & 0.1033 \\
\hline & & & $\mathrm{u}_{11}$ & 0.1357 & 0.0732 & & & & $\mathrm{u}_{11}$ & 0.2446 & 0.0582 & 0.0657 \\
\hline & & & $\mathrm{u}_{12}$ & 0.2589 & 0.1397 & & & & $\mathrm{u}_{12}$ & 0.1235 & 0.0294 & 0.0846 \\
\hline & & & $\mathrm{u}_{13}$ & 0.0750 & 0.0405 & & & & $\mathrm{u}_{13}$ & 0.1005 & 0.0239 & 0.0322 \\
\hline & & & $\mathrm{u}_{14}$ & 0.1357 & 0.0732 & & & & $\mathrm{u}_{14}$ & 0.1488 & 0.0354 & 0.0543 \\
\hline & & & $\mathrm{u}_{15}$ & 0.1357 & 0.0732 & & & & $\mathrm{u}_{15}$ & 0.1015 & 0.0242 & 0.0487 \\
\hline
\end{tabular}

Table 4. Comprehensive evaluation results of Guiyang's water resources carrying capacity.

\begin{tabular}{ccccc}
\hline Year & $\begin{array}{c}\text { Membership Degree } \\
\text { b1 to V1 Level }\end{array}$ & $\begin{array}{c}\text { Membership Degree } \\
\text { b2 to V2 Level }\end{array}$ & $\begin{array}{c}\text { Membership Degree } \\
\text { b3 to V3 Level }\end{array}$ & $\begin{array}{c}\text { Comprehensive } \\
\text { Evaluation Value }\end{array}$ \\
\hline 2009 & 0.0846 & 0.4991 & 0.4164 & 0.3507 \\
2010 & 0.0741 & 0.5273 & 0.3986 & 0.3540 \\
2011 & 0.0942 & 0.4983 & 0.4075 & 0.3590 \\
2012 & 0.2060 & 0.5160 & 0.2780 & 0.4676 \\
2013 & 0.1424 & 0.4879 & 0.3697 & 0.3977 \\
2014 & 0.3222 & 0.4659 & 0.2119 & 0.5496 \\
2015 & 0.1939 & 0.5058 & 0.3003 & 0.4521 \\
2016 & 0.2563 & 0.4210 & 0.3228 & 0.4701 \\
2017 & 0.3587 & 0.4291 & 0.2122 & 0.5659 \\
2018 & 0.3643 & 0.3527 & 0.2830 & 0.5366 \\
\hline
\end{tabular}




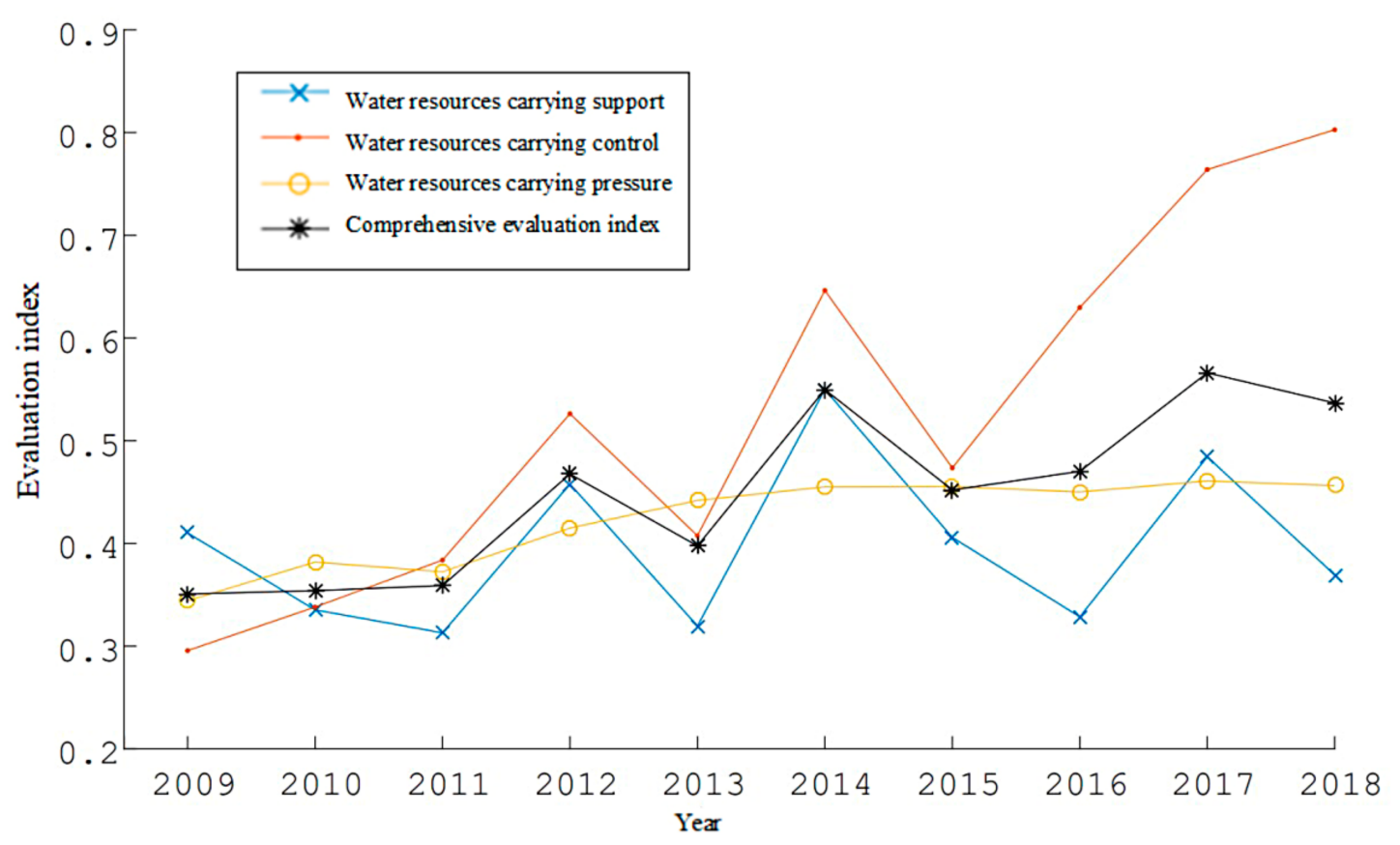

Figure 1. Evaluation result of Guiyang's water resource carrying capacity from 2009 to 2018.

\section{Analysis of Results}

The evaluation results of Guiyang's water resources carrying capacity from 2009 to 2018 is analyzed based on Table 4 and Figure 1.

(1) As for the comprehensive evaluation index, the comprehensive evaluation value of Guiyang's water resources carrying capacity from 2009 to 2018 is 0.4503 , which is close to the value of $\mathrm{H}_{2}$, indicating that the water resources carrying capacity is moderate. Except for 2012, 2014, and 2017, the comprehensive evaluation value of Guiyang's water resources carrying capacity showed a steady upward trend. Due to the sharp increase of precipitation in Guiyang in 2012, 2014, and 2017, the total amount of water resources exceeded 5 billion $\mathrm{m}^{3}$, and the water resources carrying capacity improved, which is consistent with the calculated results.

(2) From the perspective of the three subsystems, the water resources carrying support system is in a fluctuating state due to the obvious influence of the total amount of water resources. The evaluation value fluctuates greatly between 0.3 and 0.6 . Affected by the change of regional population, precipitation, urbanization, and other factors, the per capita water possession, per capita water supply, annual water production modulus, and vegetation coverage of Guiyang City fluctuated greatly from 2009 to 2018. The water resources carrying capacity control system is generally on the rise, which is closely related to Guiyang's vigorous promotion of ecological civilization construction. Thanks to the steady development of water environment management, the ecological water use rate and the compliance rate of water functional areas have been greatly improved. The water resources carrying capacity control system had large positive fluctuations in 2012 and 2014 due to the relative decrease in the utilization rate of water resources development caused by the large total amount of water resources. However, since 2015, the decrease in the total amount of water resources has not affected the rise of the water resources carrying capacity control curve, reflecting the particularly remarkable effect of water environment improvement in recent years. The water resources carrying pressure system showed a steady upward trend from 2009 to 2014. From 2014 to 2018, the evaluation value gradually stabilized at about 0.45 , and the water consumption per CNY 10,000 of GDP and per CNY 10,000 of industrial added value were greatly reduced due to the improvement of technology and productivity. However, the acceleration of economic development, 
population growth, and urbanization has brought greater pressure of water consumption, which restricts the further improvement of water resources carrying capacity. Guiyang needs to further optimize the water consumption structure to cope with the large-scale water consumption.

(3) According to the evaluation results $B\left(b_{1}, b_{2}\right.$, and $\left.b_{3}\right)$ set over the years, the membership degrees to $\mathrm{H}_{2}$ are greater than those to $\mathrm{H}_{1}$ and $\mathrm{H}_{3}$, indicating that Guiyang's development and utilization of water resources has reached a certain scale. There is still some development potential, and the water resources can maintain rapid social and economic development at the current stage. The membership degree $b_{1}$ has continuously increased from lower than 0.1 at the beginning to about 0.2 and 0.3 in recent years, and the membership degree $b_{3}$ has shown a gradual downward trend, indicating that the good components of Guiyang's water resources carrying capacity are increasing year by year, and the water resources carrying capacity is improving.

\section{Conclusions}

In this paper, with the comprehensive consideration of water resources, society, economy, ecology, etc., the evaluation system of water resources carrying capacity is divided into three subsystems: water resources carrying support, water resources carrying control, and water resources carrying pressure. The evaluation index system of Guiyang's water resources carrying capacity is constructed, the combination weight is determined by the analytic hierarchy process and the entropy method, and a model for evaluating Guiyang's water resources carrying capacity based on fuzzy analysis method is built. The model is applied to comprehensively evaluate Guiyang's water resources carrying capacity. The results show that Guiyang's water resources carrying capacity improved year by year from 2009 to 2018. At the current stage, the water resources can maintain rapid social and economic development, and there is still some development potential. In order to further improve the water resources carrying capacity, Guiyang should continue optimizing the allocation of water resources, actively promote the construction of water-saving cities, and realize the efficient development and utilization of water resources in addition to maintaining the existing achievements of water environment improvement.

Author Contributions: Data curation, S.S.; Formal analysis, Z.L.; Methodology, J.N.; Supervision, L.R.; Writing-review and editing, J.G. All authors have read and agreed to the published version of the manuscript.

Funding: This research was funded by the National Key R\&D Program of China, grant number 2018YFC1508200. The APC was funded by the National Key R\&D Program of China.

Institutional Review Board Statement: Not applicable.

Informed Consent Statement: Informed consent was obtained from all subjects involved in the study.

Data Availability Statement: The data is availability in Guiyang water resources bulletin [EB/ol] (http:/ / swglj.guiyang.gov.cn/zfxxgk/fdzdgknr/qtfdxx/szygb/) and Statistical Bulletin of Guiyang National Economic and Social Development [EB/OL] (http:/ / www.Guiyang.gov.cn/zwgk/zfxgks / fdzdgknr/tjxx/tjgb/ accessed on 31 July 2021).

Acknowledgments: This work was supported by the National Key R\&D Program of China (grant number 2018YFC1508200).

Conflicts of Interest: The authors declare no conflict of interest.

\section{References}

1. Liu, J.; Dong, S.; Li, Z. Study on Comprehensive Evaluation of China's Water Resources Carrying Capacity. J. Nat. Res. 2011, 26, 258-269.

2. Duan, C.; Liu, C.; Chen, X.; Liu, W.; Zheng, H. Discussion on the Concept and Research Methods of Regional Water Resources Carrying Capacity. Acta Geogr. Sinica 2010, 65, 82-90.

3. Li, B.; Dong, Z.; Hang, Q.; Yang, G.; Wang, C. Quantitative Study on Yancheng's Water Resources Carrying State. J. Econom. Water Res. 2019, 37, 65-69, 82. 
4. Xi, D.; Xu, X.; Han, D.; Yang, Z. Evaluation of Water Resources Carrying Capacity of the Beijing-Tianjin-Hebei Region. J. Beijing Norm. Univ. (Nat. Sci.) 2017, 53, 575-581.

5. Hong, X. Analysis of Xinjiang's Water Resources Carrying Capacity Based on Principal Component Analysis. Water Res. Plan. Design 2020, 33, 39-41, 60.

6. Guo, W.; Huang, J.; Zhang, E. Simulation Study on the Water Resources Carrying Capacity of Henan Province Based on the SD Model. J. Henan Agric. Univ. 2020, 54, 689-697.

7. Zhang, Q.; Xie, S. Analysis and Evaluation of Chongqing's Sustainable Utilization of Water Resources Based on the Water Ecological Footprint Model. J. Irrigat. Drain. 2019, 38, 93-100.

8. Sun, K.; Chen, L. Evaluation of Wuhu's Water Resources Carrying Capacity Based on the Fuzzy Analysis. China Rural Water Hydrop. 2018, 60, 121-125.

9. Dai, M.; Wang, L.; Tang, H. Study on Water Resources Carrying Capacity of Karst Regions Based on a Multi-level Fuzzy Comprehensive Evaluation Model. Bull. Soil Water Conserv. 2016, 36, 151-156.

10. Zhang, W. The Evaluation of Regional Water Resources Carrying Capacity Based on Grey Correlation Analysis and Set Pair Analysis. Master's Thesis, Hefei University of Technology, Hefei, China, 2019.

11. Zhou, Z.; Liu, S. Evaluation of Hebi's Water Resources Carrying Capacity Based on Fuzzy Comprehensive Judgment. China Rural Water Hydropower 2017, 59, 70-73, 79.

12. Li, Z.; Dong, Z.; Chen, M.; Lu, S. Evaluation of Hefei's Water Resources Carrying Capacity Based on Fuzzy Analysis. Water Res. Power 2020, 38, 43-46.

13. Jin, J.; Chen, L.; Chen, M.; Li, J.; Zhang, L.; Dong, T. Method of Water Resources Carrying Capacity Evaluation Based on Set-pair Analysis and Risk Matrix. Yangtze River 2018, 49, 35-41.

14. Gao, J. The evaluation of water resources carrying capacity in Hohhot based on fuzzy analysis method. Inner Mongol. Water Conserv. 2020, 4, 13-15.

15. Deng, X.; Li, J.; Zeng, H.; Chen, J.; Zhao, J. Analysis and Application of the Weight Calculation Method of Analytic Hierarchy Process. J. Math. Pract. Theory 2012, 42, 93-100.

16. Yang, J. Application of Improved Fuzzy Comprehensive Evaluation Method in Water Quality Evaluation. Master's Thesis, Chongqing University, Chongqing, China, 2014.

17. Dai, M.; Wang, L.; Wei, X. Spatial differentiation of water resources carrying capacity in Guangxi based on entropy weight fuzzy comprehensive evaluation model. Soil Water Conserv. Res. 2016, 23, 193-199.

18. Zou, Z.; Sun, J.; Ren, G. Weighting of Fuzzy Evaluation Factors by Entropy Method and Its Application in Water Quality Evaluation. Acta Sci. Circumst. 2005, 25, 552-556.

19. Bu, N.; Tang, D.; Yin, S. Fuzzy Comprehensive Evaluation of Zhejiang's Water Resources Carrying Capacity Based on AHP Method. Water Res. Power 2012, 30, 41-44.

20. Xing, J.; Sun, L. The evaluation of water resources carrying capacity based on factor analysis and fuzzy comprehensive evaluation method. Water Sav. Irrig. 2014, 39, 52-55, 59.

21. Guiyang Municipal Water Administration Bureau. Guiyang Water Resources Bulletin. Available online: http://swglj.guiyang. gov.cn/zfxxgk/fdzdgknr/qtfdxx/szygb/ (accessed on 20 August 2020).

22. Guiyang Municipal People's Government. Statistical Bulletin of Guiyang's National Economic and Social Development. Available online: http://www.guiyang.gov.cn/zwgk/zfxxgks/fdzdgknr/tjxx/tjgb/ (accessed on 20 August 2020). 